\title{
The Role of Health Extension in Practice Transformation and Community Health Improvement: Lessons From 5 Case Studies
}

Artbur Kaufman, $M D^{1}$

W. Perry Dickinson, $M D^{2}$

Lyle J. Fagnan, $M D^{3}$

F. Daniel Duffy, $M D^{4}$

Michael L. Parchman, MD, MPH

Robert L. Rbyne, $M D^{1}$

'Department of Family and Community Medicine, University of New Mexico, Albuquerque, New Mexico

${ }^{2}$ Department of Family Medicine, University of Colorado, Boulder, Colorado

${ }^{3}$ Department of Family Medicine, Oregon Health \& Sciences University, Portland, Oregon

${ }^{4}$ Office of Health Care Innovation, University of Oklahoma, Norman, Oklahoma

${ }^{5}$ Kaiser Permanente Washington Health Research Institute, Seattle, Washington

Conflicts of interest: authors report none

\section{CORRESPONDING AUTHOR}

Arthur Kaufman, MD

The University of New Mexico Office for Community Health

MSC09 5065

Albuquerque, NM 87131

AKaufman@salud.unm.edu

\begin{abstract}
Passage of the Patient Protection and Affordable Care Act triggered 2 successive grant initiatives from the Agency for Healthcare Research and Quality, allowing for the evolution of health extension models among 20 states, not limited to support for in-clinic primary care practice transformation, but also including a broader concept incorporating technical assistance for practices and their communities to address social determinants of health. Five states stand out in stretching the boundaries of health extension: New Mexico, Oklahoma, Oregon, Colorado, and Washington. Their stories reveal lessons learned regarding the successes and challenges, including the importance of building sustained relationships with practices and community coalitions; of documenting success in broad terms as well as achieving diverse outcomes of meaning to different stakeholders; of understanding that health extension is a function that can be carried out by an individual or group depending on resources; and of being prepared for political struggles over "turf" and ownership of extension. All states saw the need for long-term, sustained fundraising beyond grants in an environment expecting a short-term return on investment, and they were challenged operating in a shifting health system landscape where the creativity and personal relationships built with small primary care practices was hindered when these practices were purchased by larger health delivery systems.
\end{abstract}

Ann Fam Med 2019;17:S67-S72. https://doi.org/10.1370/afm.2409.

\section{INTRODUCTION}

$\mathrm{H}$ ealth extension is a model being developed and implemented across the country that was adapted from the agricultural Cooperative Extension Service, which traditionally linked land-grant university resources with rural farm economy needs through county-based agents. The health extension model similarly deploys local agents to assist primary care practices and the communities they serve in improving patient and community health, acting as a bridge between academic and community knowledge and expertise, extending resources and programs into remote and underserved areas, and linking community priorities to research and service initiatives of the health system..$^{1-3}$ Health extension helps address adverse social determinants of health, which play a far greater role in health than does the health care system. ${ }^{4,5}$

Interest in health extension accelerated with the inclusion of Section 5405 in the Patient Protection and Affordable Care Act (ACA), ${ }^{6}$ establishing a Primary Care Extension Program with 2 roles: promoting primary care practice transformation toward a patient-centered medical home, and decreasing health disparities and improving the health of communities. ${ }^{7}$ Section 5405 created the window of opportunity for states to consider implementing this model. Two grant programs from the Agency for Healthcare Research and Quality (AHRQ) — Infrastructure for Maintaining Primary Care Transformation (IMPaCT) and EvidenceNOW-have supported 22 states in applying the concepts of health extension. ${ }^{8}$ 
Through IMPaCT, AHRQ awarded \$4 million for a 2-year cooperative agreement with institutions in 4 states: New Mexico, Oklahoma, North Carolina, and Pennsylvania. Each award funded state-level quality improvement initiatives and practice transformation infrastructure applying the primary care extension model to small primary care practices. Each awarded state had to collaborate with 3 or 4 partner states to assist them in developing, expanding, and improving their state-level extension models. A total of 17 states thus provided multiple examples of how a health extension model could be built. ${ }^{5}$

The EvidenceNOW initiative, a subsequent grant program, is a large, $\$ 112$ million investment by AHRQ that funds 7 regional cooperatives in 12 states working with approximately 1,500 small to medium-sized primary care practices. The cooperatives help practices adopt the latest evidence-based cardiovascular risk guidelines by applying health extension approaches in quality improvement and practice transformation. ${ }^{8}$ AHRQ chose ESCALATES-Evaluating System Change to Advance Learning and Take Evidence to Scale-as the team to evaluate EvidenceNOW using a multimethod approach.

Five of the state programs in New Mexico, Oklahoma, Oregon, Colorado, and Washington have gone beyond a focus on practice transformation to address social determinants at the community level-both aspects of the ACA's Section 5405 Primary Care Extension Program. In this article, we summarize the development of health extension and insights gained from these 5 states that have developed this model in different environments, responding to different opportunities and challenges. Insights were collected through a series of semistructured interviews with the principal investigators of these 5 health extension-oriented initiatives funded by the IMPaCT and EvidenceNOW grants.

\section{CASE STUDIES: STORIES FROM 5 STATES New Mexico: Health Extension Rural Offices} The Health Extension Regional Offices (HEROs) program was created a decade ago, modeled on elements of the agricultural Cooperative Extension Service, and initially deployed university-employed agents across the state to address social determinants of health and link priority community health needs with University of New Mexico (UNM) resources. ${ }^{2}$ The scope of HEROs expanded to address primary care practice transformation with awards from AHRQ's 2 key grants. Currently, 10 HEROs serve rural and urban communities. Mixed funding sources-institutional, research grants, foundation, endowment, Medicaid, and county government-allow for long-term engagement, and HEROs are also a key element of sister initiatives involving Community Health Workers (CHWs), helping to train them to work with individuals having high social and medical needs. Funding for UNM's CHWs is more economically sustainable because of their short-term return on investment (eg, reduced emergency department visits and hospitalizations) generated by screening patients for adverse social determinants and intervening quickly. ${ }^{9}$

There was concern from several quarters when health extension emerged in New Mexico: the Cooperative Extension Service feared UNM's use of the term extension would confuse communities and threaten public funding sources. The Area Health Education Center (AHEC) and local Department of Health believed they already did the work of health extension and should be the rightful recipients of funding. Over time, however, HEROs engaged in partnerships with each of these entities, sharing resources through grant funding and complementing each other's strengths in the field. ${ }^{10}$

During both the IMPaCT and EvidenceNOW grants, HEROs discovered that practices' highest priority was not necessarily the goal of the grant. Instead, practices requested help with such needs as staff and clinician recruitment, continuing medical education for office staff, and strategies for addressing the social determinants of health both within their clinic walls and in the community.

\section{Oklahoma: County Health Improvement Organizations}

Oklahoma's health extension program emerged out of its practice-based research network. With IMPaCT, Oklahoma supported 22 County Health Improvement Organizations (CHIOs) across the state, each forming a local, nonprofit 501c3 organization composed of health and health care stakeholders and governed by a community board. ${ }^{11}$ With EvidenceNOW, Oklahoma was able to expand its health extension infrastructure for $\mathrm{CHIOs}$, including practice facilitators (called practice enhancement assistants or PEAs), academic detailers, partnerships for health information technology, and administration, forming the OK Primary Healthcare Improvement Cooperative. $\mathrm{CHIOs}$ are branching out and partnering with other organizations on such targets as suicide and hypertension prevention programs.

Despite program growth and success, this initiative faces many challenges, especially sustainability. The health extension infrastructure has been grant funded. One plan was to embed CHIOs in AHECs, but AHECs have almost disappeared in Oklahoma because of budget cuts. The Department of Health was an important partner, but their budgets have suffered severe losses. 
Hindering sustainability of the $\mathrm{CHIO}$ is its dependency on grants, which call the tune, making it difficult to develop a coherent improvement plan. Practice facilitation has not caught on outside grant-funded initiatives. Although very supportive, the University of Oklahoma does not have the institutionalized service arm needed for sustaining health extension. Perhaps of greater threat are the seismic shifts in the larger health system that has adopted a market-based approach to absorbing primary care practices, focusing on market rather than on community health needs, and not entirely embracing the value of primary care microsystems as the drivers of healthy people and their communities.

\section{Oregon: Practice Enhancement Research Coordinators}

At Oregon Health \& Sciences University, the Oregon Rural Practice-Based Research Network (ORPRN) evolved as a resource for developing collaborations reaching beyond the clinic walls to address the upstream social determinants of health as it engaged in community-based research. To facilitate this evolution, ORPRN has deployed 9 regionally based practice enhancement research coordinators (PERCs) who bridge the needs of researchers, practices, and the community. These coordinators represent an important, university-linked health extension model that shares a bidirectional, campus-community benefit orientation with the New Mexico HEROs program. ${ }^{12}$ PERCs are deployed regionally with a cohort of practices.

The most difficult engagement door to open is that of the primary care office. Few other health extension organizations have had a comparable level of success reaching primary care practices. Building trusted relationships is critical, yet resource intensive. PERCs were a key to recruitment success with EvidenceNOW: 1 in 3 practices had a prior relationship with the organizations enrolled, whereas only 1 in 20 did not. ${ }^{13}$ Practices and communities value the sustained relationship, noting that "ORPRN was here yesterday, today and will be with us tomorrow" (personal communication, Lyle Fagnan, MD, 2018). Sustaining these relationships is a major challenge as grants and contracts do not support the need to maintain continuity between projects.

Change in the health care system toward increasing ownership of primary care practices by larger organizations is one of the greatest challenges to health extension programs. These systems control the agenda, disempowering individual practices and their communities. In 2005, $58 \%$ percent of ORPRN practices were physician owned, 5 years later, only $37 \%$ were. ${ }^{14}$ The loss of physician autonomy has resulted in a loss of innovation and the pioneering spirit that has traditionally characterized practices partaking in practice-based research network. A major strength of ORPRN's health extension program has been its independence. Although based at Oregon Health \& Sciences University, the program can serve as an honest broker for practice and community needs without first hearing, "What's in it for the university?" ORPRN works across the entire state with the PERCs as connectors, boundary spanners, and knowledge brokers between practices and organizations.

\section{Colorado: Regional Health Connectors}

The University of Colorado has well-documented success in primary care practice redesign with less of an emphasis on social determinants and community health. Sharing strategies with IMPaCT grant recipients in Oklahoma and New Mexico, Colorado developed health extension as a blended model of their historic strength in primary care transformation with an added component of community health improvement. ${ }^{15}$ When they received the EvidenceNOW grant concurrently with a State Innovation Model grant funded by the Centers for Medicare \& Medicaid Services, their health extension model development accelerated. A large steering committee representing various public health, behavioral health, and social service agencies, as well as grassroots community groups, was formed early in the process, building on impetus from the IMPaCT grant. This process led to creation of the Colorado Regional Health Connector (RHC) program, which helped bridge primary care, public health, and other community health organizations at the local level. The RHC model was jointly funded by the State Innovation Model and EvidenceNOW, and was informed by collaboration with New Mexico's HEROs program. Eventually, 21 RHCs were deployed across the state, each responsible for a distinct geographic region.

Major challenges remain, including lack of appreciation and understanding on the part of policymakers and payers for the value of practice support and RHCtype services, and premature pressure to demonstrate positive quantitative outcomes from the RHC efforts. But Colorado leaders believe that the relationships and trust being built will be the enduring outcomes. Having a single umbrella organization under the university might have moved the process more quickly, but would not have allowed the slower, more organic growth and ownership of many organizations that is so important for future sustainability.

\section{Washington: Practice Coaches}

Washington and Oregon partnered with 2 organizations on the submission of their EvidenceNOW grant proposal: Qualis Health served as the Regional Extension Center for implementing meaningful use of 
electronic health records and population health management, and Oregon's ORPRN provided their deep knowledge of community engagement and how to help the whole community, not just the practice. Where Qualis Health focused on diligently fulfilling their subcontract obligations, ORPRN was "all about the relationship"; the first meeting of the 2 organizations was akin to "people in suits meeting people in tie-dye t-shirts and sandals" (personal communication, Michael Parchman, MD, MPH, 2018). During the evolution of health extension within the EvidenceNOW project, the focus shifted from monitoring clinic data to practices' priority needs, including assistance with office management and billing software.

Washington faced a fractured landscape of organizations functioning independently of each other, with their own practice coaches funded by disparate organizations. For those focusing only on their business model as quality improvement consultants, health extension concepts were beyond their skill or interest. Further, although CHWs in Washington play a role in health extension via their focus on social determinants, there are political challenges, and CHWs fear being dominated by a medical model of practice.

Sustainability was hindered by smaller practices being bought by larger hospitals and systems. As the concept of health extension became better known across the state, however, its functions shifted to local agencies, government, hospitals, and Federally Qualified Health Centers through contracts for work on specific projects_optimizing opioid prescribing, reducing tobacco use, and controlling hypertension.

\section{LESSONS LEARNED}

Several important observations emerged from the extensive experiences of these 5 states and their leaders. The 7 lessons that follow are not the only lessons from this work, but are those we view as most important to the success or sustainability of their programs.

(1) Relationships are key. Whether they are called HEROs, PEAs, PERCs, RHCs, or coaches, health extension agents have an integrative beelike function, cross-pollenating best practices between patients, clinics, public health entities, universities, and communities. Their value is realized in the degree to which they establish long-term, personal relationships and trust. Even in an environment where health system and hospital mergers can threaten long-established physicianpatient care continuity and undermine community trust in the commitment of new systems to tend to priority local needs, health extension agents can offer new systems a continuity of trusted relationships and linkages to needed resources.
(2) Funding must be sustainable. Funding sources for health extension tend to be short term, rely on soft money, and vary with local economic and professional opportunities. Proponents of health extension must take the long view. Some program planners have linked health extension to more easily funded components of community engagement such as $\mathrm{CHW}$ programs; others promote services of health extension for targeted grant projects. The 2 key federal funding opportunities described in this article not only provided resources for the development of a health extension infrastructure, but more importantly, created opportunity for the development of a state-based, nationwide community of learning, through the cross-state learning design of the IMPaCT grants and the formation of cooperatives and cross-cooperative learning communities in the EvidenceNOW initiative.

(3) Important target outcomes will vary across stakeholders. The target outcome chosen depends on the audience. For payers, the impact of health extension on outcomes such as emergency department visits and hospitalizations is important. For a health care delivery system, it may be a priority to reduce loss of patients to other health systems while preparing for success in new payment models. For communities, it may be encouraging youth to stay in school, to grow a local health workforce, and to help improve the local economy. The ESCALATES evaluation team has documented varied targets of extension programs, from taking evidence to scale ${ }^{8}$ to reducing electronic health record challenges ${ }^{16}$ to alleviating clinician burnout in small primary care practices. ${ }^{17}$

(4) Health extension is a collaborative multidisciplinary undertaking. Much like the agricultural Cooperative Extension Services, which operates locally through agents with different expertise, health extension also has agents with different skill sets such as practice facilitation, information technology expertise for data mining through electronic health records, and training in addressing social determinants using community resources. Programs should be flexible, however, when determining the arrangement that best meets their community needs and available resources. In resource-rich environments, this role can be filled by several people, whereas in remote environments, a single person may fulfill all health extension functions.

(5) Challenges will arise over power and control. Each state faced struggles around turf and ownership of their health extension program. Each was unprepared for the reactions of established groups. In New Mexico, for example, community concerns that the university was taking over intensified when grant dollars became available for health extension. The best strategy to combat this conflict is engaging with 
groups expressing concern, demonstrating a willingness to share resources, and, in some cases, creating an advisory board representing all interests. In addition, the goals of specific grants sometimes diverted resources away from practice or community priorities_-recruiting physicians and nurses, improving billing efficiencies, and accessing medical library resources electronically. These inadvertent consequences must also be anticipated and addressed.

(6) Incentives are currently misaligned. Accountable care systems and value-based purchasing are coming, but most incentives remain aligned with a fee-for-service model. Health extension models being developed are therefore more suited to the future rather than fully applicable today. Further, although most social determinants such as education, housing, income, food, and social inclusion are embedded in the skill set of health extension and social services, they lie outside of the skill set of most current health care systems and clinicians. ${ }^{18}$

(7) Building coalitions takes time. Most health extension programs concluded that it is worth the effort to spend extra time building coalitions, gaining broad insights and contributions from different institutions and sectors, and generating shared ownership over the initiative. The current health care landscape is characterized by competing health systems, each with its own business objectives and missions. Health extension has the potential to link stakeholder interests in an effort to improve community health.

\section{CONCLUSIONS}

Health extension is a viable service model, integrating social determinants of health into primary care while expanding linkages between primary care and community resources. It has grown into a meaningful vehicle for improving the quality of primary care practices while addressing the health of communities served by those practices. Implementing a health extension model during the current transition and upheaval in the health care system presents challenges. The growing national interest in health extension was powered by federal grant funding emerging from different agencies. The outcomes and lessons learned from these ever-enlarging grants call for an even more expansive initiative that focuses more deliberately on the community health component of primary care innovation. Mindful of the overriding importance of social determinants in community health, the new funding should increase clinic impact on community health via support of cross-sectoral linkages and community capacity building where success is defined by metrics of community health improvement. We also recom- mend investing in local leaders trusted by communities who can bridge the interests of health systems, clinics, and community. Beyond initial grant funding, each institution and state is adapting to local circumstances, finding unique ways of broadening ownership and marketing the model to diverse beneficiaries. We believe it is wise to seek sustainable funding for different components of the health extension model that appeal to different funders and stakeholders. Success can be documented in terms of publications on processes and outcomes. Outcomes meaningful to Medicaid-managed care insurers may differ from outcomes of interest to the local, nonprofit community. The lead convener of health extension may vary by state, depending on historical leadership roles and various stakeholders' trust in the convener. The convener could be the university as in the case of Oregon or New Mexico, a population health management organization as in the case of Washington, or a position shared by a university and statewide grant-making foundation as in the case of Colorado. Successful leaders of health extension therefore should take the long view, value the slow process of building coalitions and developing broad ownership, and link their model creatively with funding sources that benefit from upstream investments.

To read or post commentaries in response to this article, see it online at http://www.AnnFamMed.org/content/17/Suppl_1/S67.

Key words: health extension; primary care; organizational change; outreach; population health; social determinants of health; practice-based research

Submitted August 31, 2018; submitted, revised, March 6, 2019; accepted April 17, 2019.

Funding support: This work was supported by grant numbers 1U18HSO20890, 1U18HS020972, 1R18HS23904, and 1R18HS023908 from the Agency for Healthcare Research and Quality (AHRQ).

Disclaimer: The authors are solely responsible for this document's contents, findings, and conclusions. The findings and conclusions do not necessarily represent the views of AHRQ; therefore, readers should not interpret any statement in this report as an official position of AHRQ or of the US Department of Health and Human Services.

Acknowledgments: The New Mexico authors thank our colleagues from the EvidenceNOW Southwest core team: Carolina Nkouaga, Molly Bleecker, Danelle Callan, and Angelica Solares, who provided insight into the background information for this article as well as assistance in performing the semistructured interviews with health extension leadership; the Health Extension Officers around the state whose expertise in community engagement has greatly informed this article: Juliana Anastasoff, Alisha Herrick, Elaine Luna, Toyese Oyeyemi, Marnie Nixon, Francisco Ronquillo, Evelyn Rising, and Helen Tso; and our partners at Healthlnsight New Mexico and the New Mexico Primary Care Association for their technical assistance in practice transformation on the EvidenceNOW Southwest project; and our patient and insightful AHRQ EvidenceNOW Southwest Project Officer, Robert J. McNellis, PA, who guided us through the complexities of our 2-state collaboration. 


\section{References}

1. Grumbach K, Mold JW. A health care cooperative extension service: transforming primary care and community health. JAMA. 2009; 301(24):2589-2591.

2. Kaufman A, Powell W, Alfero C, et al. Health extension in New Mexico: an academic health center and the social determinants of disease. Ann Fam Med. 2010;8(1):73-81.

3. Kaufman A, Rhyne RL, Anastasoff J, et al. Health extension and clinical and translational science: an innovative strategy for community engagement. J Am Board Fam Med. 2017;30(1):94-99.

4. Schroeder SA. Shattuck Lecture. We can do better-improving the health of the American people. N Engl J Med. 2007;357(12): 1221-1228.

5. Health Extension Toolkit. http://www.healthextensiontoolkit.org. Accessed Aug 30, 2018.

6. The Patient Protection and Affordable Care Act, 42 USC §18001 et seq (2010). http://housedocs.house.gov/energycommerce/ppacacon. pdf. Published May 2010.

7. Phillips RL Jr, Kaufman A, Mold JW, et al. The primary care extension program: a catalyst for change. Ann Fam Med. 2013;11(2): 173-178.

8. Ono SS, Crabtree BF, Hemler JR, et al. Taking innovation to scale in primary care practices: the functions of health care extension. Health Aff (Millwood). 2018;37(2):222-230.

9. Johnson D, Saavedra P, Sun E, et al. Community health workers and Medicaid managed care in New Mexico. J Community Health. 2012; 37(3):563-571.

10. Kaufman A, Boren J, Koukel S, Ronquillo F, Davies C, Nkouaga C. Agriculture and health sectors collaborate in addressing population health. Ann Fam Med. 2017;15(5):475-480.
11. Mold JW. A cooperative extension service for primary care in Oklahoma. J Okla State Med Assoc. 2011;104(11-12):414-418.

12. Fagnan LJ. Moving upstream-health extension and primary care. J Am Board Fam Med. 2017;30(1):10-12.

13. Fagnan LJ, Walunas TL, Parchman ML, et al. Engaging primary care practices in studies of improvement: did you budget enough for practice recruitment? Ann Fam Med. 2018;16(Suppl 1):S72-S79.

14. Fagnan LJ, Morris C, Shipman SA, Holub J, King A, Angier H. Characterizing a practice-based research network: Oregon Rural Practice-Based Research Network (ORPRN) survey tools. J Am Board Fam Med. 2007;20(2):204-219.

15. Anastasoff J, Backlund JP, Kaufman A. Screening the health home for social determinants: integrating the social mission into primary care practice improvident via health extension. Presented at: Beyond Flexner Alliance Conference; April 9-11, 2018; Atlanta, GA.

16. Hemler JR, Hall JD, Cholan RA, et al. Practice facilitator strategies for addressing electronic health record data challenges for quality improvement: EvidenceNOW. J Am Board Fam Med. 2018;31(3): 398-409.

17. Edwards ST, Marino M, Balasubramanian BA, et al. Burnout among physicians, advanced practice clinicians and staff in smaller primary care practices. J Gen Intern Med. 2018;33(12):2138-2146.

18. Robert Wood Johnson Foundation. Health care's blind side: the overlooked connection between social needs and good health. https://www.rwjf.org/en/library/research/2011/12/health-care-sblind-side.html. Published Dec 1, 2011. Accessed Aug 30, 2018. 